\title{
COVID-19-Associated Bifacial Weakness with Paresthesia Subtype of Guillain-Barré Syndrome
}

\author{
(D).L. Hutchins, (D).H. Jansen, (D) A.D. Comer, (D)R.V. Scheer, (D) G.S. Zahn, (D)A.E. Capps, (D).M. Weaver, and (D) N.A. Koontz
} O-

\begin{abstract}
SUMMARY: We report a case of bifacial weakness with paresthesia, a recognized Guillain-Barré syndrome subtype characterized by rapidly progressive facial weakness and paresthesia without ataxia or other cranial neuropathies, which was temporally associated with antecedent coronavirus 2019 (COVID-19). This case highlights a potentially novel but critically important neurologic association of the COVID-19 disease process. Herein, we detail the clinicoradiologic work-up and diagnosis, clinical course, and multidisciplinary medical management of this patient with COVID-19. This case is illustrative of the increasingly recognized but potentially underreported neurologic manifestations of COVID-19, which must be considered and further investigated in this pandemic disease.
\end{abstract}

ABBREVIATIONS: BFP = bifacial weakness with paresthesia; $C N=$ cranial nerve; COVID-19 = coronavirus 2019; GBS = Guillain-Barré syndrome; HSV = herpes simplex virus; Ig = immunoglobulin; PCR = polymerase chain reaction; SARS-CoV-2 = Severe Acute Respiratory Syndrome coronavirus 2

$\mathbf{S}$ evere Acute Respiratory Syndrome coronavirus 2 (SARS$\mathrm{CoV}-2)$ is the novel coronavirus responsible for the pandemic coronavirus disease 2019 (COVID-19). First identified in Wuhan, China, in late December 2019, ${ }^{1}$ global transmission increased rapidly, with the first case of COVID-19 reported in the United States on January 19, 2020 ${ }^{2}$ and $>1.34$ million cases and nearly 81,000 deaths reported in the United States as of May 12, 2020. ${ }^{3}$ While the typical presentation is respiratory symptoms (dry cough and dyspnea), a number of other associated symptoms have been described, including fever, diarrhea, abdominal pain, fatigue, and altered mental status. Potential neurologic manifestations are increasingly recognized but may be underreported. ${ }^{4-8}$ A potential association between COVID19 and Guillain-Barré syndrome (GBS) has been suggested in 2 recent editorial correspondences; ${ }^{7,8}$ however, the temporal relationship of GBS antecedent to COVID-19 symptomatology raised a question of causality in 1 report. ${ }^{7}$ In this brief report, we detail a case of bifacial weakness with paresthesia subtype

Received April 19, 2020; accepted after revision May 22.

From the Departments of Neurology (K.L.H., A.D.C., R.V.S.), Emergency Medicine (J.H.J., G.S.Z., L.M.W.), Radiology and Imaging Sciences (A.E.C., N.A.K.), and Otolaryngology-Head \& Neck Surgery (N.A.K.), Indiana University School of Medicine, Indianapolis, Indiana.

Katherine L. Hutchins and Jaclyn $\mathrm{H}$. Jansen are co-first authors.

Please address correspondence to Nicholas A. Koontz, MD, 550 N University Blvd, Room 0063, Indianapolis, IN 46202; e-mail: nakoontz@iupui.edu; @nakoontz

- Indicates open access to non-subscribers at www.ajnr.org

Indicates article with supplemental on-line tables.

http://dx.doi.org/10.3174/ajnr.A6654
GBS that demonstrated a postinfectious temporal association with COVID-19, developing approximately 2 weeks after the onset of COVID-19 symptomatology. This Health Insurance Portability and Accountability Act-compliant investigation was reviewed by the institutional review board at our medical school and was (BFP) exempt from further review and monitoring.

\section{Case Report}

A 21-year-old man presented to the emergency department with progressive 4-day history of fever, cough, dyspnea, diarrhea, nausea, headache, and sinonasal congestion. Aside from a medical history of hypertension, prediabetes, and class I obesity, the patient was otherwise healthy and denied tobacco, alcohol, substance abuse, or recent travel. Vital signs were remarkable for a body temperature of $37.5^{\circ} \mathrm{C}$, blood pressure of $116 / 57 \mathrm{~mm} \mathrm{Hg}$, pulse of 76 beats per minute, and oxygen saturation of $95 \%$ on room air. Physical examination documented nonlabored respirations and clear lungs. Neurologic examination was intact. Chest radiographs (Fig 1) demonstrated patchy bilateral air space opacities without lobar consolidation.

A nasopharyngeal swab was performed, and a respiratory pathogen panel was negative for all tested pathogens. Additionally, nasopharyngeal and oropharyngeal swab specimens were sent to an outside private laboratory for SARS-CoV-2 real-time reverse transcriptase polymerase chain reaction (PCR) assay. He was discharged home with pulse oximetry monitoring, self-isolation instructions, and strict return precautions. 

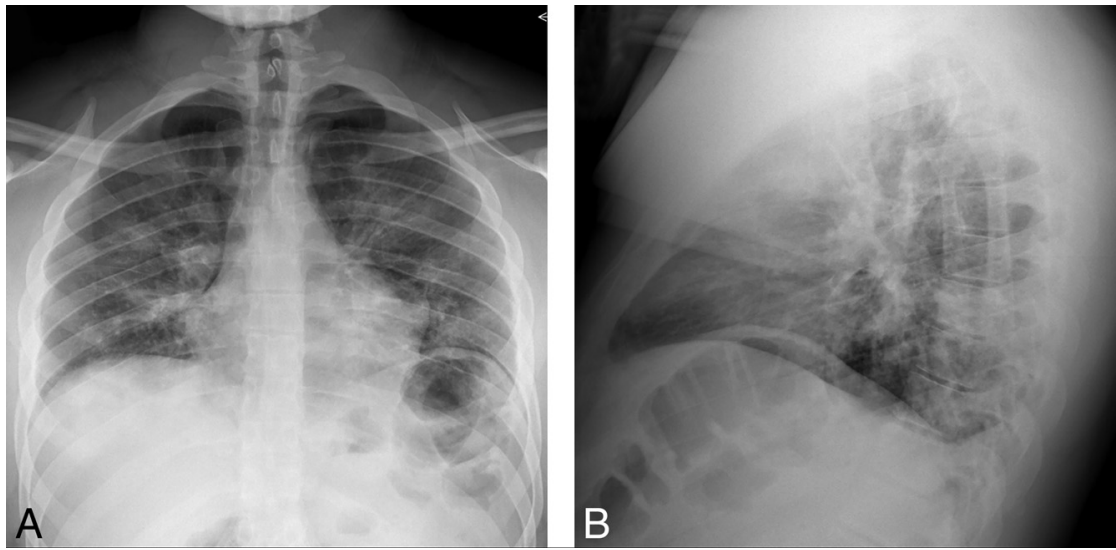

FIG 1. Initial chest radiographs in a patient with COVID-19 and subsequent bifacial weakness and paresthesia subtype Guillain-Barré syndrome. Posterior-anterior $(A)$ and lateral $(B)$ upright chest radiographs demonstrate low lung volumes with patchy bilateral air space opacities, but no lobar consolidation.
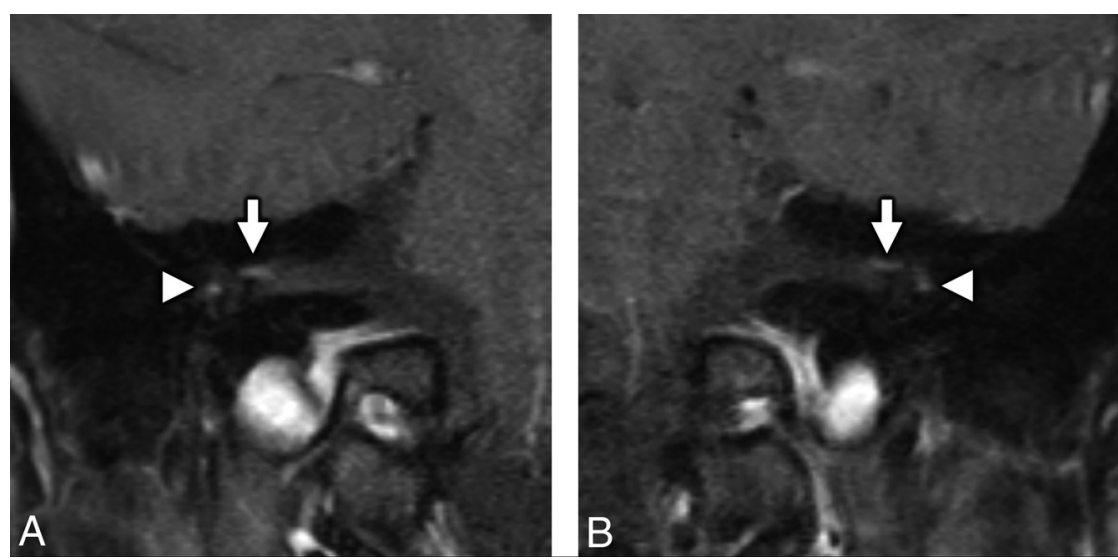

FIG 2. MR imaging of the temporal bones in a patient with antecedent COVID-19 and new-onset bifacial weakness and paresthesia subtype Guillain-Barré syndrome. Coronal postcontrast T7weighted fat-saturated MR imaging of the right $(A)$ and left $(B)$ temporal bones demonstrates abnormal "tuft-like" enhancement at the anterior-superior fundus of the internal auditory canal bilaterally (white arrows), corresponding to the distal canalicular segments of the facial nerves (CNVII). Note additional contrast enhancement along the tympanic segments of the facial nerve bilaterally (white arrowheads), which is greater in degree than typically encountered. Enhancement along the canalicular segments of the facial nerves (white arrows) is always considered abnormal on MR imaging, though mild tympanic segment enhancement is considered within normal limits.

During the next 24 hours, the patient experienced increased dizziness with oxygen saturation falling into the mid-80s documented by pulse oximetry. He returned to the emergency department febrile (body temperature of $39.1^{\circ} \mathrm{C}$ ), mildly tachycardic (102 beats per minute), tachypneic (28 breaths per minute), and hypoxic ( $89 \%$ on room air). Chest radiographs demonstrated increased bilateral air space opacities, and a complete blood count revealed lymphopenia (absolute lymphocyte count of $0.7 \mathrm{~K} /$ $\mathrm{mm}^{3}$ ). He was admitted for oxygen support and monitoring, and blood oxygenation was weaned from $2 \mathrm{~L}$ by nasal canula to room air. He was discharged home on hospital day 4 , and his sent-out testing confirmed COVID-19 positivity the day after discharge.

He initially did well with convalescence at home, but on day 16 of illness, he began to experience right-sided facial numbness and weakness. During 24 hours, his symptoms became bilateral and resulted in severe dysarthria, necessitating a return to the emergency department. $\mathrm{He}$ also reported associated hypogeusia. Neurologic examination demonstrated a bilateral lower motor neuron pattern of facial weakness with otherwise normal cranial nerve $(\mathrm{CN})$ examination findings, preserved strength and sensation in all extremities, and intact muscle stretch reflexes. He was admitted for observation and underwent MR imaging of the brain and temporal bones, as well as fluoroscopically guided lumbar puncture for CSF sampling. The CSF was negative for bacterial culture and stain and demonstrated normal glucose levels $(65 \mathrm{mg} / \mathrm{dL})$, no leukocytes, and mildly elevated protein levels (49 mg/dL). MR imaging demonstrated abnormal enhancement of the facial (CNVII) and abducens (CNVI) nerves bilaterally, as well as the right oculomotor nerve (CNIII) (Figs 2-4).

The patient was discharged with stable facial weakness, no progression of symptoms, and oxygen saturation of $99 \%$ on room air. Neurology outpatient follow-up was arranged with multiple CSF and serum lab results pending. On day 19 of illness, he reported new subjective bilateral lower extremity weakness, bilateral upper extremity paresthesia, and continued facial weakness, prompting readmission for further work-up and treatment. Repeat neurologic examination demonstrated unchanged bifacial weakness, but new grade 4/5 weakness in the deltoids and hip flexors bilaterally, as well as diffuse areflexia. MR imaging of the total spine was performed, which did not reveal any suspicious spinal cord signal abnormality or abnormal enhancement of the cord or cauda equina. Electromyography and nerve conduction studies demonstrated findings consistent with an acute sensorimotor polyneuropathy with both demyelinating and axonal features (On-line Tables 1-4).

For religious reasons, he declined treatment with intravenous immunoglobulin (Ig) and alternatively underwent treatment with 5 cycles of plasma exchange, which he tolerated well with slight improvement in facial weakness and paresthesia. Findings of CSF labs and serologies remained negative except for serum herpes simplex virus (HSV), immunoglobulin G (IgG), and immunoglobulin $\mathrm{M}(\operatorname{IgM})$, and the patient was discharged to inpatient rehabilitation. He declined a repeat lumbar puncture that was offered before discharge. 


\section{MATERIALS AND METHODS}

\section{Diagnostic Testing for COVID-19}

At the initial emergency department visit, chest radiography (Fig 1) was performed, and nasopharyngeal swab specimens were sent for multiplex reverse transcription polymerase chain reaction via a NxTAG Respiratory Pathogen Panel (Luminex) to assess adenovirus, influenza $A$, influenza $B$, parainfluenza 1, parainfluenza 2, parainfluenza 3, parainfluenza 4, Chlamydia pneumoniae, Mycoplasma pneumoniae, bocavirus, coronavirus, respiratory syncytial virus A, respiratory syncytial virus B, metapneumovirus, rhinovirus, and enterovirus infection (On-line Table 5). Additional nasopharyngeal and oropharyngeal swab specimens were sent to an outside private laboratory (Viracor Eurofins Clinical Diagnostics) for SARS-CoV-2 real-time reverse-transcriptase polymerase chain reaction testing. During subsequent hospital readmissions and before final discharge, COVID-19 status was tested
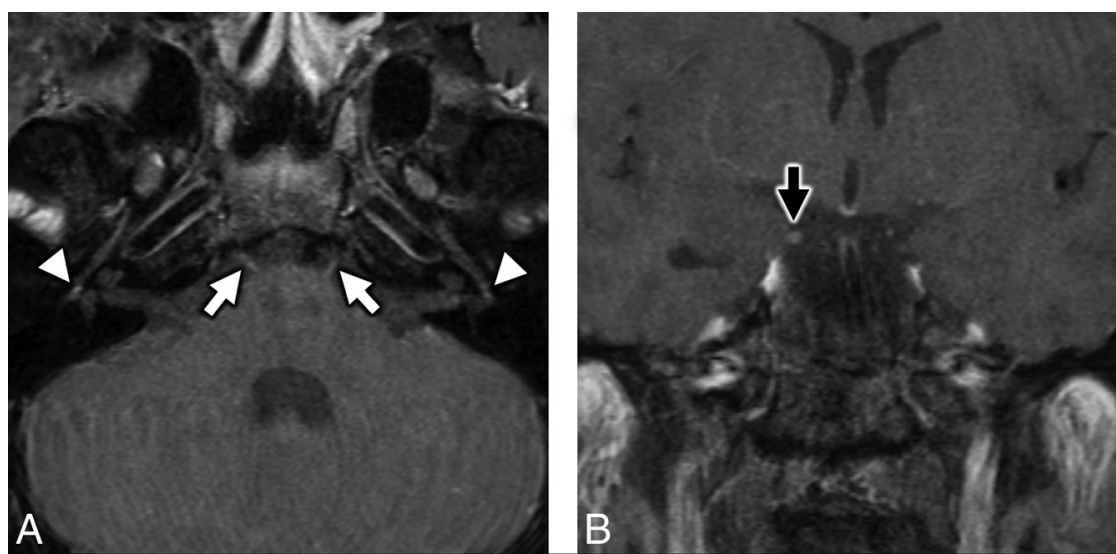

FIG 3. MR imaging of the temporal bones in a patient with antecedent COVID-19 and new-onset bifacial weakness and paresthesia subtype Guillain-Barré syndrome. Axial postcontrast T1weighted fat-saturated MR imaging of the temporal bones $(A)$ shows subtle-but-abnormal enhancement along the cisternal segments of the abducens nerves (CNVI) bilaterally (white arrows), as well as subtle enhancement along the tympanic segments of the intratemporal facial nerves (CNVII) bilaterally (white arrowheads). Coronal postcontrast T1-weighted fat-saturated MR imaging $(B)$ shows subtle asymmetric enhancement along the cisternal segment of the right oculomotor nerve (CNIII, black arrow). with nasopharyngeal/oropharyngeal swabs and SARS-CoV-2 PCR assays performed at our hospital laboratory.

\section{Diagnostic Testing for GBS}

MR imaging of the brain, temporal bones, and total spine was performed (Figs 2-4). Respective serologic, stool, and urine antibody tests, including antiganglioside (GM1, GD1b, and GQ1b IgG and IgM), aquaporin-4 receptor (IgG), HIV 1/2, HSV 1/2 (IgG and IgM), cytomegalovirus (IgM), Mycoplasma pneumoniae (IgG and IgM), Borrelia burgdorferi (IgG and $\operatorname{IgM}$ ), Bartonella species (IgG and $\operatorname{IgM}$ ), and syphilis (Venereal Disease Research Laboratory test), were obtained (On-line Tables 6-9). A serum angiotensin-converting enzyme level was also obtained to screen for sarcoidosis. CSF was tested for cell count, protein and glucose levels, red blood cell count, and infectious etiologies, including bacterial and fungal culture and stain, meningoencephalitis panel (varicella zoster virus, cytomegalovirus, enterovirus, HSV 1, HSV 2, human herpesvirus 6, human parechovirus, EpsteinBarr virus, Cryptococcus neoformans/ gattii, Escherichia coli, Haemophilus influenzae, Listeria monocytogenes, Neisseria meningitidis, Streptococcus agalactiae, and Streptococcus pneumoniae), Bartonella species, syphilis, and Lyme disease (On-line Table 10).

\section{RESULTS}

\section{Specimen Testing for COVID-19}

Positive SARS-CoV-2 viral status was confirmed via initial sent-out nasopharyngeal/oropharyngeal swabs. On subsequent hospital readmission, internal PCR reconfirmed SARS-CoV2 viral status. Repeat PCR before discharge was negative for SARS-CoV-2 detection.
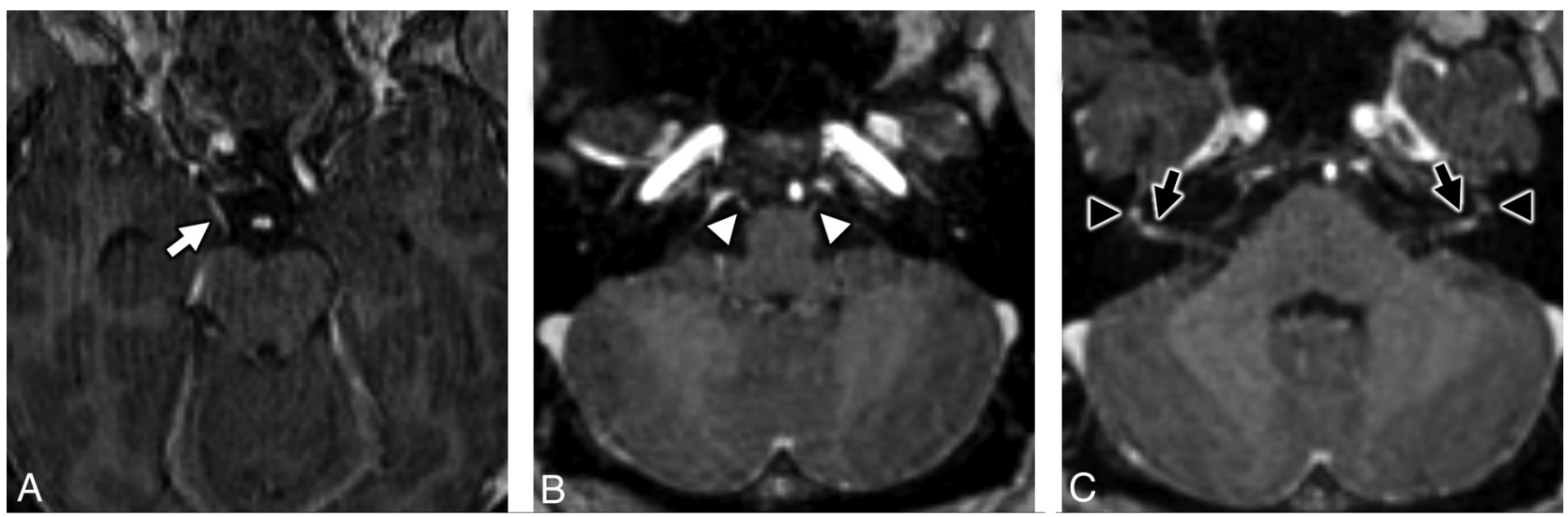

FIG 4. MRI of the brain in a patient with antecedent COVID-19 and new onset bifacial weakness and paresthesias subtype Guillain-Barré syndrome. Axial post-contrast Tl-weighted SPoiled Gradient-Recalled (SPGR) MRI shows abnormal enhancement of the right oculomotor nerve (CNIII, white arrow, A), the cisternal segments of the abducens nerves (CNVI) bilaterally (white arrowheads, B), the distal canalicular segments of the facial nerves (CNVII) bilaterally (black arrows, C), and the proximal tympanic segments of the intratemporal facial nerves (CNVII) bilaterally (black arrowheads, C). 


\section{Specimen Testing for GBS}

Serologic testing for infectious and inflammatory mimics was unremarkable apart from elevated HSV-1 IgG of $>8.0$ and initial HSV-1/2 IgM of 1.07 index values (On-line Tables 6-9). Repeat HSV-1/2 IgM at 10 days postpresentation was further elevated at 2.39 index values. CSF protein was mildly elevated $(49 \mathrm{mg} / \mathrm{dL}$, which corrected to $46 \mathrm{mg} / \mathrm{dL}$ when accounting for $2425 \mathrm{red}$ blood cells) with no white blood cells. CSF stains were negative for bacterial or fungal organisms, and cultures demonstrated no growth. The CSF meningoencephalitis panel and Bartonella species, syphilis, and Lyme disease tests were also negative (On-line Table 10).

\section{DISCUSSION}

Our report details a case of bifacial weakness and paresthesia subtype Guillain-Barré syndrome that was temporally associated with COVID-19. In our case, a patient with antecedent community-acquired COVID-19 pneumonia developed rapidly progressive bilateral facial weakness, extremity paresthesia, and mild proximal extremity weakness without ataxia or other cranial neuropathies 16 days after the onset of COVID-19 symptomatology. He exhibited clinicoradiologic features most consistent with GBS, affecting CNVII bilaterally and lacking antiganglioside antibodies, concordant with prior reports of BFP subtype GBS. ${ }^{8-10}$ Our patient demonstrated imaging findings that align with prior reports of GBS following antecedent viral infections. ${ }^{11,12}$ Enhancement of the cranial nerves is a known MR imaging finding in GBS, , ,13,14 and most interesting, our patient demonstrated abnormal enhancement of CNVI bilaterally and the right CNIII, which were clinically asymptomatic. On the basis of clinical grounds, we suspect that this indicates subclinical disease in the BFP variant of GBS, rather than the Miller Fisher variant of GBS, ${ }^{15}$ given lack of ophthalmoparesis and ataxia. Our patient did not demonstrate any typical spinal imaging manifestations of GBS, which may include thickening of the cauda equina nerve roots with enhancement, often with a ventral nerve root predilection. ${ }^{16,17}$

To date, a recent editorial correspondence reports a small observational series of 5 cases of suspected COVID-19-associated GBS, ${ }^{8}$ but no prior detailed clinical reports have been published. In a previously reported case of possible COVID-19-associated GBS in a patient with recent travel to Wuhan, the patient manifested an atypical temporal profile with acute bilateral lower extremity weakness as an initial presenting symptom and subsequent development of COVID-19 pneumonia on hospital day 8, raising concern for coincidental disease processes and possible nosocomial infection. ${ }^{7}$

Our case demonstrates a postinfectious temporal relationship between antecedent SARS-CoV-2 infection and GBS symptomatology, but positive HSV serologies remain a confounder. Although ubiquitous, HSV infection has been reported as an extremely rare antecedent to GBS. ${ }^{18-22}$ Whether in our case the GBS was directly caused by COVID-19, the COVID-19-associated systemic inflammatory response unmasked or exacerbated an HSV-mediated GBS, or the patient simply manifested unfortunately timed coexisting disease processes remains unknowable. However, we note prior immunologic research by Ziganshin et al $^{19}$ that demonstrated an increased risk of GBS triggering in simultaneous polyviral infection, including HSV, which might have important implications for the pathoetiology of GBS in our patient. Most important, the temporal association of antecedent COVID-19 and subsequent development of GBS symptomatology in our patient necessitates physicians being made aware of this possible linkage consideration.

GBS is a diverse disorder of the peripheral nervous system characterized by acute immune-mediated neuropathy, which may be broadly categorized into acute motor axonal neuropathy, acute inflammatory demyelinating polyradiculoneuropathy, and acute motor-sensory axonal neuropathy, ${ }^{23-25}$ as well as subdivided into clinically distinct variants, such as Miller Fisher variant and BFP., ${ }^{9,10,15}$ GBS is commonly associated with immune stimulation from antecedent bacterial or viral infection, including gastrointestinal infection and upper respiratory tract infections. ${ }^{23-26}$ GBS is thought to be due, in great part, to molecular mimicry, ${ }^{23}$ whereby antibodies created in response to infectious antigens cross-react with neurons and the myelin sheath, causing demyelination and/or axonal damage. GBS is typically multiphasic, with rapid progression, a prolonged plateau, and variable recovery with approximately $15 \%-20 \%$ permanent disability at 1 year. ${ }^{23,27}$ GBS-related mortality is approximately $5 \%$, often due to neuromuscular respiratory failure and autonomic dysfunction. ${ }^{23,27}$ Early intravenous immunoglobulin or plasma exchange, along with supportive care, is the mainstay of therapy.

There are limited data regarding neurologic manifestations of COVID-19 infection. A recently published retrospective, observational case series from Mao et $\mathrm{al}^{4}$ suggested that neurologic manifestations of COVID-19 may be underrecognized. They report neurologic manifestations in up to $36 \%$ of hospitalized patients with COVID-19, including dizziness (16.8\%), headache (13.1\%), and altered level of consciousness (7.5\%), as well as impaired taste (5.6\%), smell (5.1\%), and vision (1.4\%), but no cases of GBS. COVID-19 has recently been implicated as a presumptive cause of acute hemorrhagic necrotizing encephalopathy, which may represent an intracranial manifestation of a COVID-19-related cytokine storm. ${ }^{5}$ There is also suspicion that the prothrombotic and proinflammatory states associated with COVID-19 may increase the incidence of cerebrovascular disease, ${ }^{4,6}$ though there is a paucity of evidence in the currently published literature. Neurotropic animal and human coronaviruses have been identified, ${ }^{28}$ and coronavirus-associated GBS has been previously reported, including Middle East Respiratory Syndrome. ${ }^{29,30}$ Given genetic similarities among the coronaviruses, it is conceivable that similar neuropathology might be seen with SARS-CoV-2.

\section{CONCLUSIONS}

This report details a case of postinfectious acute peripheral polyneuropathy in a patient recently diagnosed with and convalescing from community-acquired COVID-19, highlighting the multidisciplinary collaboration required to diagnose and manage this complex patient. The clinicoradiologic features and temporal profile are most consistent with a BFP subtype of GBS. Given the paucity of data regarding neurologic manifestations of COVID- 
19, this case highlights the need for continued close attention to and reporting of its potential neurologic sequelae.

Disclosures: Richard V. Scheer-UNRELATED: Expert Testimony: Hume Smith Geddes Green \& Simmons. Lindsay Weaver-UNRELATED: Employment: Indiana State Department of Health, Comments: Chief Medical Officer.

\section{REFERENCES}

1. Zhu N, Zhang D, Wang W, et al; China Novel Coronavirus Investigating and Research Team. A novel coronavirus from patients with pneumonia in China, 2019. N Engl J Med 2020;382: 727-33 CrossRef Medline

2. Holshue ML, DeBolt C, Lindquist S, et al; Washington State 2019nCoV Case Investigation Team. First case of 2019 novel coronavirus in the United States. N Engl J Med 2020;382:929-36 CrossRef Medline

3. Centers for Disease Control and Prevention. Coronavirus disease 2019 (COVID-19): cases in U.S. 2020. https://www.cdc.gov/coronavirus/ 2019-ncov/cases-updates/cases-in-us.html\#2019coronavirus-summary. Accessed May 13, 2020

4. Mao L, Jin H, Wang M, et al. Neurologic manifestations of hospitalized patients with coronavirus disease 2019 in Wuhan, China. JAMA Neurol 2020 Apr 10. [Epub ahead of print] CrossRef Medline

5. Poyiadji N, Shahin G, Noujaim D, et al. COVID-19-associated acute hemorrhagic necrotizing encephalopathy: CT and MRI features. Radiology 2020 Mar 31. [Epub ahead of print] CrossRef Medline

6. Zhang Y, Xiao M, Zhang S, et al. Coagulopathy and antiphospholipid antibodies in patients with Covid-19. N Engl J Med 2020;382: e38 CrossRef Medline

7. Zhao H, Shen D, Zhou H, et al. Guillain-Barre syndrome associated with SARS-CoV-2 infection: causality or coincidence? Lancet Neurol 2020;19:383-84 CrossRef Medline

8. Toscano G, Palmerini F, Ravaglia S, et al. Guillain-Barre Syndrome associated with SARS-CoV-2. N Engl J Med 2020;19:383-84 CrossRef Medline

9. Wakerley BR, Yuki N. Isolated facial diplegia in Guillain-Barre syndrome: bifacial weakness with paresthesias. Muscle Nerve 2015; 52:927-32 CrossRef Medline

10. Kim JK, Oh SY, Sohn EH, et al. When is facial diplegia regarded as a variant of Guillain-Barre syndrome? J Peripher Nerv Syst 2015;20: 32-36 CrossRef Medline

11. Hygino da Cruz LC Jr, Nascimento OJ, Lopes F, et al. Neuroimaging findings of Zika virus-associated neurologic complications in adults. AJNR Am J Neuroradiol 2018;39:1967-74 CrossRef Medline

12. Wu S, Zeng $Y$, Lerner $A$, et al. Nervous system injury and neuroimaging of Zika virus infection. Front Neurol 2018;9:227 CrossRef Medline

13. Zuccoli G, Panigrahy A, Bailey A, et al. Redefining the GuillainBarre spectrum in children: neuroimaging findings of cranial nerve involvement. AJNR Am J Neuroradiol 2011;32:639-42 CrossRef Medline

14. Fulbright RK, Erdum E, Sze G, et al. Cranial nerve enhancement in the Guillain-Barre syndrome. AJNR Am J Neuroradiol 1995;16:92325 Medline
15. Al Othman B, Raabe J, Kini A, et al. Update: the Miller Fisher variants of Guillain-Barre syndrome. Curr Opin Ophthalmol 2019;30: 462-66 CrossRef Medline

16. Byun WM, Park WK, Park BH, et al. Guillain-Barre syndrome: MR imaging findings of the spine in eight patients. Radiology 1998;208: 137-41 CrossRef Medline

17. Dodson SC, Koontz NA. Spinal manifestations of systemic disease. Radiol Clin North Am 2019;57:281-306 CrossRef Medline

18. Hao Y, Wang W, Jacobs BC, et al. Antecedent infections in Guillain-Barre syndrome: a single-center, prospective study. Ann Clin Transl Neurol 2019;6:2510-17 CrossRef Medline

19. Ziganshin $\mathrm{RH}$, Ivanova OM, Lomakin YA, et al. The pathogenesis of the demyelinating form of Guillain-Barre sndrome (GBS): proteopeptidomic and immunological profiling of physiological fluids. Mol Cell Proteomics 2016;15:2366-78 CrossRef Medline

20. De Fine Olivarius B, Buhl M. Herpes simplex virus and GuillainBarre polyradiculitis. BMJ 1975;1:192-93 CrossRef Medline

21. Yuki N, Susuki K, Odaka M, et al. Overlapping Guillain-Barre syndrome and Bickerstaff's brainstem encephalitis associated with anti-GQ1b IgG antibody after herpes simplex virus infection. Acta Neurol Scand 2001;104:57-60 CrossRef Medline

22. Hunt DP, Muse VV, Pitman MB. Case records of the Massachusetts General Hospital: case 12-2013-an 18-year-old woman with pulmonary infiltrates and respiratory failure. $N$ Engl J Med 2013;368: 1537-45 CrossRef Medline

23. Willison HJ, Jacobs BC, van Doorn PA. Guillain-Barre syndrome. Lancet 2016;388:717-27 CrossRef

24. Grimaldi-Bensouda L, Alperovitch A, Besson G, et al; Lucien Abenhaim for the GBS-PGRx Study Group. Guillain-Barre syndrome, influenzalike illnesses, and influenza vaccination during seasons with and without circulating A/H1N1 viruses. Am J Epidemiol 2011;174:326-35 CrossRef Medline

25. Dardiotis E, Sokratous M, Tsouris Z, et al. Association between Helicobacter pylori infection and Guillain-Barre syndrome: a meta-analysis. Eur J Clin Invest 2020;50:e13218 CrossRef Medline

26. Petras M, Lesna IK, Danova J, et al. Is an increased risk of developing Guillain-Barre syndrome associated with seasonal influenza vaccination? A systematic review and meta-analysis. Vaccines (Basel) 2020;8:E150 CrossRef Medline

27. Rajabally YA, Uncini A. Outcome and its predictors in GuillainBarre syndrome. J Neurol Neurosurg Psychiatry 2012;83:711-18 CrossRef Medline

28. Desforges M, Le Coupanec A, Brison E, et al. Neuroinvasive and neurotropic human respiratory coronaviruses: potential neurovirulent agents in humans. Adv Exp Med Biol 2014;807:75-96 CrossRef Medline

29. Kim JE, Heo JH, Kim HO, et al. Neurological complications during treatment of Middle East respiratory syndrome. J Clin Neurol 2017;13:227-33 CrossRef Medline

30. Sharma K, Tengsupakul S, Sanchez O, et al. Guillain-Barre syndrome with unilateral peripheral facial and bulbar palsy in a child: a case report. SAGE Open Med Case Rep 2019;7:2050313X19838750 CrossRef Medline 